\title{
Hereditariedade e crime
}

\section{A. Almeida Júnior}

Falando a um auditório em que predominam juristas e estudantes de direito, julgo de meu dever, antes de entrar própriamente no tema desta conferencia, fixar certas noções e atitudes fundamentais da Genética moderna.

\section{I - Noções fundamentais}

1. Os caracteres humanos, sejam morfológicos ou funcionais, fisiológicos ou psíquicos, normais ou patológicos, resultam de duas ordens de fôrças: os fatores genéticos e os fatores ambientais. São genéticos os fatores que residem nos coromosomas celulares, isto é, naquelas 24 alças microscópicas que a investigação científica assinala em cada célula reprodutora humana. Para a constituição do ovo, - elemento inicial do novo indivíduo, - o genitor masculino contribui com 24 cromosomas, onde se alojam os milhares de fatores (ou "gens") hereditários que ele transmite ao filho. O genitor feminino, por sua vez, contribui, por intermédio do óvulo, com outros 24 cromosomas, em que se situam, do mesmo modo, milhares de "gens", simétricamente correspondentes aos de procedência paterna. É êsse, - e sómente êsse, - o patrimônio genético, ou hereditário, que, por via

(1) Conferência proferida em 2 de setembro de 1947, no Centro de Estudos Criminológicos de São Paulo. 
biológica, os pais transmitem aos filhos: 24 pares de microscópicos cromosomas, equivalentes a milhares de pares de "gens".

2. Todos os outros fatores são de natureza ambiental. Entram a atuar, uns, antes do nascimento, na vida pre-natal ou intra-uterina; os demais, após o nascimento, na vida postnatal. Há, entre êsses fatores ambientais, os que residem nos humores orgânicos e penetram nas células, constituindo, assim, o ambiente interior; e há os que compõem o ambiente exterior, - sem que, aliás, se possa sempre estabelecer limite nítido entre um $e$ outro.

3. E comum discriminar os "caracteres" humanos em dois grupos: os de origem hereditária e os de origem ambiental (ou "não hereditária"). Tal discriminação não corresponde à realidade: todos os nossos caracteres - os morfológicos como os funcionais - resultam da colaboração das duas ordens de fatores. $\in$ verdade que em relação a uns: as fôrças genéticas preponderam; e que para outros sobressai a contribuição do ambiente. Mas em todos se dá a cooperação; de sorte que é possível, dentro de certos linites, modificar determinado caráter através de um dêstes dois mecanismos: ou alterando a hereditariedade, ou mudando o ambiente.

4. Suposição vulgar igualmente inexata, é a de que a hereditariedade consiste na transmissão de "caracteres": pais altos ou pais inteligentes, por exemplo, transmitiriam aos filhos a estatura elevada ou a inteligência. Não; a hereditariedade não é a transmissão de caracteres, mas a de fatores. Cada genitor transmite ao produto certo número de "gens" - alguns dos quais para a estatura ou para a inteligência, etc. - "gens" que se expressarão de maneira mais ou menos intensa, segundo as condições ambientais. O patrimônio genético é, em última análise, um conjunto de fôrças latentes, de potencialidades, as quais se realiza- 
rão ou não; e, se realizadas, terão esta ou aquela intensidade, conforme sejam, ou não, favorecidas pelo ambiente (2).

5. Merece atenção particular a controvérsia entre os que acreditam na fácil modificabilidade do plasma germinativo, e os que afirmam a fixidez dêsse plasma. Lombroso, por exemplo, aceitando como boas as conclusões de Marino, declara que a herança criminal, quando proveniente de pais jovens, impele à violência, isto é, ao roubo e à agressão física; e, se proveniente de pais velhos, arrasta aos delitos de esperteza (3). Maneira implícita de admitir que os "gens", de que os pais são portadores, vão sofrendo modificações com a idade. O mesmo autor, e com ele muitos outros, julgam que o álcool e a sífilis podem atuar sôbre o plasma germinativo, prejudicando-o; e explicam por essa forma a frequência de criminosos entre os filhos de alcoólatras e de sifilíticos.

A Genética moderna, se bem que não considere resolvido o problema, tende cada vez mais a negar tais possibilidades. O plasma germinativo é estável e não o atingem de maneira eficaz nem as toxinas microbianas, nem o álcool (4). Cada individuo transmite, pois, aos descendentes, sem melhorá-lo mas também sem peorá-lo, o mesmo plasma germinativo que seus ascendentes lhe legaram. Da incapa-

(2) Um sociólogo norte-americano, Walter C. Reckless (Criminal Behavior, N. York, 1940, pag. 188), ao discutir as relações entre hereditariedade e crime, mostra ignorar a concepção acima: "um caráter veŕdadeiramente hereditário (?), diz ele, não precisa das fôrças externas par expressar-se; por si."

(3) Cesar Lombroso - El Delito, sus Causas y Remedios, trad. esp. de C. B. Quinós, Madrid, 1902, pag. 236, etc.

(4) É extensa a literatura sôbre o assunto. Na revista "Medicina, Cirurgia, Farmácia" (Rio, julho-agosto, 1937), o prof. ANdrÉ Dreyfus publicou excelente "mise-au-point" da questāo referente ao heredo-alcoolismo e à heredo-sífilis. Em "Alcohol and Man", editado por Haven Emerson (N. Y., 1933), Charles Stockard e Charles Davenport têm dois documentados trabalhos a respeito da alegada ação degenerativa do álcool. Em "Alcohol, Science and Society", série de conferências efetuadas em 1945, na Universidade 
cidade para deteriorar só escapam alguns agentes de grande penetração, como os raios $\mathrm{X}$, magistralmente estudados por Hermann Muller, e certas radiações da bomba atômica.

\section{II - Os antigos métodos de indagação}

Os antigos métodos de indagação, postos a serviço do propósito de verificar o papel da hereditariedade na produção do crime, eram essencialmente dois, - mais precisamente, - era um só, aplicado em duas coletividades, a dos aglomerados sociais e a das famílias.

1. Em referência a certos aglomerados sociais - as "raças", como displicentemente se dizia, - afirmavam-se coisas surpreendentes. Comentava-se a existência de tribos nas quais a propensão para a honradez e a veracidade era hereditária, em contraste com outras, que transmitiriam de pais a filhos, por herança, a inclinação para o furto ou para o latrocínio. A "dellinquência hereditária", comum entre os judeus e os ciganos, tomaria, nessas "raças", a forma preferencial de crimes contra a propriedade. A elevada proporção de criminosos negros, nos Estados Unidos, em confronto com a menor proporção de criminosos brancos, provaria irrecusàvelmente 0 papel da herança sôbre a má conduta.

2. Mostrava-se, do mesmo passo, como avultava, em certas famílias, a incidência do crime. Era de rigor, neste particular, recorer, depois de alguns exemplos avulsos, aos casos clássicos da família Kallikak, estudada por GoDdARD nos Estados Unidos; da família Jukes, que Dugdale anali-

de Yale, o tema voltou a debate. "Os elementos germinais — disse então JELLINEK - poderiam ser prejudicados pelas concentrações muito elevadas de álcool; mas eles se acdam de tal maneira protegidos que, antes que aquelas concentrações fossem atingidas, o genitor alcoólico teria morrido. É necessário muito menos álcool para matar o homem, ou a mulher, do que para prejudicar a célula germinativa" (pag. 1,13). 
sou desde 1877; de família Zero, cuja documentação foi reunida por Jorger, na Suiça; e várias outras.

3. A crítica mais importante que a tais estudos se pode fazer, é a de que nenhum deles permite distinguir, na criminalidade, a parcela devida ao fator genético da que provenha das influências ambientais. Será a herança, ou serão as condições sociais e a educação, as fôrças que, em determinadas tribos, perpetuam o furto? Por que explicar a criminalidade dos negros norte-americanos pela hereditariedade, e não pelas péssimas condições econômicas e culturais em que vivem? $O$ vício da argumentação não passara despercebido a Aschaffenburg, o qual, embora criminologista da velha escola, assim comenta a conclusão em favor da hereditariedade criminal: "Creio que não é justo atribuir demasiada importância a êste modo de transmissão, assim como ao fato, que não raro se observa, de que há famílias inteiras e até localidades que se distinguem por uma atividade criminal intensa. A criança que vive desde os mais tenros anos no meio de criminosos, adapta-se ao seu modo de pensar e não pode atingir à concepção de outras idéias. O crime perde seu caráter de ato condenável; a punição, o de uma desonra; quando muito é esta considerada um inconveniente que inevitàvelmente acompanha a profissão. Renunciarei, pelo mesmo motivo, a descrever a célebre família Juke com o seu imenso exército de criminosos, prostitutas, idiotas e asilados, ou outras árvores genealógicas análogas" (5).

\section{III - Os novos métodos. O estudo dos gêmeos}

Os métodos antigos, que acabamos de recordar, não permitiam reconhecer, nos indivíduos, a parte da hereditariedade e a do ambiente. $\mathrm{E}$ os métodos modernos?

(5) G. Aschaffenburg - Crime e Repressão, trad. port. da ed. alemã de 1903, por S. G. Lisboa, Lisboa, 1904, pag. 112 . Tн. Riвот, em L'Hérédité Psychologique, 9. ed., Paris, 1910, pág. 95-96, 
1. Comecemos pelo caso dos criminosos que, em fins do século XVIII, a Inglaterra remeteu para certas colônias da Austrália. Ali se fixaram, ali procriaram, e seus filhos, instalados nesse meio diferente, viveram em paz e prosperaram. Diante disso, qual a conclusão a extrair-se? Que não ocorrem fatores genéticos para o crime? Seria temerário. O mais que se pode admitir é esta alternativa: ou não existem êsses fatores, ou, se existem, as condições favoráveis do ambiente podem contrariá-los e impedir-lhes a expressão.

2. 'Análoga interpretação comportam os estudos de filhos de criminosos afastados desde cedo dos próprios lares, e educados em lares honestos, ou em internatos. ANNE Roe, professora adjunta de Psicologia na Universidade de Yale, comunica o que observou com relação a 61 indivíduos que, retirados quando pequenos do convívio dos pais, foram criados por famílias extranhas. Dos 61 indivíduos, 25 provinham de genitores normais; os 36 restantes tinham pais anormais (alcoólatras, delinquentes, pervertidos sexuais). Com o decorrer do tempo, os adotivos chegaram à idade adulta (entre 22 e 40 anos de idade) : nenhum filho de alcoólatra se tornou alcoólatra nem criminoso; nenhum filho de criminoso se tornou criminoso nem alcoólatra (6). Eis-nos, pois, em face da mesma alternativa: ou a hereditariedade não pesa em relação ao crime, ou, se pesa, o bom ambiente pode contrabalançá-la.

refer, como prova da hereditariedade das "paixões", a geofagia observada por Humbold nas regióes tropicais. Os pais comem terra; os filhos padecem da mesma impulsão mórbida. Ora, a geofagia provém, mais comumente, da ancilostomose: as idores epigástricas, que a doença provoca, se acalmam pela ingestão de terra. Obeservações insuficientes, como essa, acrescidas de interpretação apressada, levaram a formular os principios que estamos comentando.

(6) Alcohol, Science and Society - Yale Summer School of Alcohod Studies, New Haven, 1945, pág. 115-127. 
3. Desta dúvida nos vai tirar o mais moderno, e também o mais preciso dos métodos de investigação para a hereditariedade humana: o estudo dos gêmeos.

Existem, dêstes, como se sabe, duas categorias: os gêmeos "fraternos" (bivitelinos, dizigóticos), e os gêmeos "idênticos" (univitelinos, monozigóticos). Aqueles provêm de ovos diversos: têm, pois, patrimônios hereditários desiguais entre si; podem ser de sexos diferentes, de diferentes grupos sanguíneos; seus olhos, seus cabelos podem não coincidir na côr; seus desenhos papilares apresentam-se distanciados quanto ao aspecto. Éstes, — os gêmeos "idênticos" — nasceram do mesmo ovo (que se separou em duas ou mais porções iguais) - têm idênticos patrimônios genéticos; são do mesmo sexo, do mesmo grupo sanguíneo; seus olhos, seus cabelos apresentam-se da mesma côr, suas cristas papilares oferecem desenhos muito aproximados.

4. O primeiro cientista a buscar, no estudo dos gêmeos, elementos p̀ara investigar as proporções recíprocas entre a fôrça dos fatores genéticos e a dos fatores ambientais ("nature and nurture"), foi Francis Galton (7). Reuniu ele muitos casos de gêmeos idênticos (ou aparentemente "idênticos", pois que ao seu tempo os processos para o diagnóstico estavam apenas começando). Dois gêmeos, por exemplo, ainda meninos de escola, gostavam de pregar peças a tôda gente; as queixas contra eles eram quotidianas; mas, pôsto em face dos dois, o queixoso não sabia distinguir o culpado. Um dos diretores da escola, então, com receio de castigar o inocente, deixava os dois impunes; o diretor seguinte, porém, não querendo deixar impune o culpado, castigava os dois. Num outro par, - dois moços, - um deles,

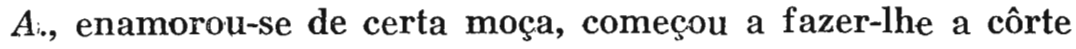
visitando-a em casa dela; mas algumas vezes, não podendo ir vê-la, mandava seu irmão $B$. desempenhar-se dessa função, o que sucedia sem que a moça désse pela troca. 0

(7) Francis Galton - Inquiries into Human Faculty, Londres, 1883. 
par referido pelo grande médico francês Trousseau (par que figura na coleção de Galton), além de enorme semelhança física, apresentava uma extranha semelhança patológica: os dois membros do par sofriam de ásma e de "oftalmia reumática". Pois quando um, em Paris (conta Trousseau), tinha o seu episódio de oftalmia, o outro, em Viena, também tinha o seu; se um, ao passar por certa cidade, era tomado pela ásma o outro, ao chegar à mesma cidade, não escapava ao referido mal. Dessa investigação original e pioneira, pôde GaLton extrair as seguintes conclusões: 1) o fator genético ("nature") é muito mais poderoso que o fator ambiental ("nurture"), desde que não se extremem as variações dêste último; 2) só as profundas diferenças ambientais podem distanciar entre si aqueles que a hereditariedade fez idênticos.

Vejamos, todavia, os resultados das investigações recentes, servidas por técnicas mais precisas.

\section{IV - Os gêmeos estudados por Newman, Freeman e Holzinger}

Newman (geneticista), Freeman (psicólogo) e Holzinger (estatístico) publicaram, em 1937, os resultados de minucioso estudo a que submeteram 119 pares de gêmeos, assim distribuidos: a) 50 pares de gêmeos idênticos, criados juntos; b) 50 pares de gêmeos fraternos, também criados juntos; c) 19 pares de gêmeos idênticos criados separadamente. Foram todos examinados sob os mais variados aspectos: altura (em pé e sentados), pêso, largura e comprimento da cabeça, cristas digitais, motricidade, grau de inteligência emotividade, temperamento, etc.

1. Quanto aos do primeiro grupo, - o dos gêmeos idênticos criados juntos, - como coincidiam, para os dois membros de cada par, as duas ordens de fatores, - os genéticos e os ambientais, - era de esperar que se apresenitassem extremamente parecidos em tudo, nos caracteres 
fúsicos, nos psicológicos e nos morais. $\mathrm{E}$ assim foi : as várias medidas tomadas, inclusive os "tests" psicológicos, quase nenhuma diferença revelaram de um gêmeo para outro, dentro do mesmo par.

2. Submetidos, porém, à observação os gêmeos do segundo grupo, - gêmeos fraternos criados juntos, - nos quais em relação a cada par coincidia o ambiente, mas não o patrimônio genético, - foram muito mais pronunciadas as diferenças. Eis aqui, a título de ilustração, alguns resultados :

MÉDIA DAS DIFERENÇAS ENTRE OS MEMBROS DE CADA PAR

\begin{tabular}{|c|c|c|}
\hline Caracteres & Idênticos & Fraternos \\
\hline 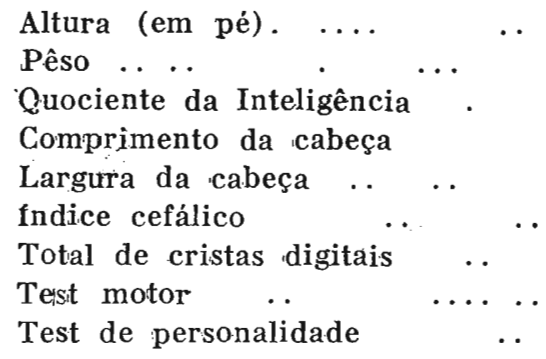 & $\begin{array}{l}1,7 \mathrm{~cm} . \\
4,1 \mathrm{lb} . \\
5,9 \\
2 ; 9 \mathrm{~mm} . \\
2,8 \mathrm{~mm} \text {. } \\
0,016 \\
5,9 \\
19,3 \\
5,3\end{array}$ & $\begin{array}{l}4,4 \mathrm{~cm} . \\
10,0 \mathrm{lb} \\
9,9 \\
6.2 \mathrm{~mm} \text {. } \\
4,2 \mathrm{~mm}, \\
0,028 \\
22,3 \\
29,0 \\
6,7\end{array}$ \\
\hline
\end{tabular}

Não influisse o equipamento genético, - mas só o ambiente, - sôbre os caracteres apontados, e as diferenças entre os membros de cada par de gêmeos idênticos, bastante exíguas, seriam igualmente exíguas com referência aos de cada par de gêmeos traternos. Os resultados acima levam-nos, porém, a corclusão oposta: variando o equipamento genético, variam também (ainda que o ambiente se conserve o mesmo) a altura, o pêso, as medidas cefálicas, e, de igual maneira, a inteligência, a motricidade e o temperamento.

3. Os dados relativos ao terceiro grupo, - o dos gêmeos idênticos criados separadamente, - são do máximo 
interêsse, pois permitem vêr qual a ação exercida por fatores ambientais diversos sôbre criaturas portadoras do mesmo patrimônio genético. Quais foram êsses resultados? Viram os autores que em relação a certos caracteres - estatura, comprimento ou largura da cabeça, - a diversidade de ambientes não acarretou divergências apreciáveis; o que mostra que aqueles caracteres dependem quase que exclusivamente da hereditariedade. Para outros resultados, porém, - pêso corporau, grau de inteligência, aproveitamento escolar, - foram grandes os desvios: em outros termos, ainda que duas criaturas hajam nascido com fatores genéticos exatamente iguais para o pêso, para a inteligência ou para a capacidade de esfôrço intelectual, poderão, se postas em ambientes diversos, apresentar pêsos, graus de inteligência ou rendimentos escolares muito diferentes.

4. Em conjunto, os dados apurados por Newman, FreEMAN e Holzinger indicam que "os caracteres físicos são os menos influenciados pelo ambiente; a inteligência é mais influenciada; o aproveitamento escolar, ainda mais; a "personalidade", ou temperamento, muito mais que o resto". Por outro lado (comentam os autores), se os fatores ambientais que atuam sôbre dois indivíduos se equivalem, ou pouco diferem entre si, é óbvio que as diferenças existentes entre êsses indivíduos provêm das fôrças genéticas; se, ao contrário, os dois possuem o mesmo patrimônio genético, mas vivem em ambientes diversos, devem atribuir-se às ações ambientais as suas diferenças. Ora, os resultados, a que se chega através da observação, permitem afirmar que os bons fatores genéticos podem ser danificados pelo mau ambiente; e que, por outro lado, os maus fatores genéticos podem atenuar-se graças ao influxo de um ambiente favorável: "aquilo que a hereditariedade faz, tambẻm o ambiente pode fazê-lo" (8).

(8) Newman, Freeman e Holzinger - Twins: A Study of Heredity and Evironment, Chicago, 1937. 


\section{V - Os gêmeos e a criminalidade}

Mas já é tempo de vermos o que tem produzido, na investigação da etiologia do crime, o processo galtoniano baseado em observações comparativas de gêmeos.

1. Coube ao cientista alemão Johannes LANGe, em 1930, inaugurar êstes estudos (9). Encontrou ele, nas prisões de seu país, assentamentos sôbre 30 criminosos, cada um dos quais era membro de um par de gêmeos, — ambos os gêmeos pertencendo ao mesmo sexo. Investigação posterior mostrou-lhe que 13 pares correspondiam a gêmeos idênticos; os outros 17 eram de gêmeos fraternos. Como se haviam comportado, em relação ao Código Penal, os irmãos gêmeos dos 30 criminosos? Tinham também infringido a lei? Descobriu LANGE o seguinte: dos 13 pares de gêmeos idênticos, em 10 casos os dois membros do par haviam cometido crimes; quanto aos 17 pares de gêmeos fraternos, sómente em 3 tinham os dois irmãos entrado em conflito com a lei. Se, pois, entre dois indivíduos que nascem com o mesmo equipamento genético, um deles se torna criminoso, o outro "tem pouca probabilidade de escapar a igual destino" Essa nítida influência do fator genético sôbre as impulsões para o delito, que o simples resultado estatístico põe desde logo em destaque, torna-se ainda mais evidente quando (como fez LANGE) se analisam individualmente os pares de gêmeos idênticos. Um dos gêmeos era arrombador: seu irmão também era arombador. Um gêmeo fôra condenado por este-

(9) Johannes Lange - Crime and Destiny (trad. inglesa), 1930. Citamos atraviés de H. S. Jennings - Genetics, N. York, 1935, págs. 202-204; David Abrahamsen - Crime and the Human Mind, N. York, 1944, págs. 41-42, e Bentuey Glass - Genes and the Man. N. York, 1943, págs. 216-218. 
lionato: seu companhciro era igualmente estelionatário. Em certo par, os dois se distinguiam pela prática de pequenos delitos contra a propriedade; em outro, os dois bebiam, e, quando embriagados, puxavam faca; em um terceiro, ambos se mostravam destituidos da menor simpatia humana, ambos profundamente egoistas. "Em todos êsses pares - sublinha LANGE - o tipo de crime é o mesmo; a carreira criminal começa aproximadamente na mesma idade, a conduta de ambos os membros perante o tribunal e na cadeia é inteiramente igual". Em referência aos gêmeos fraternos, mudam as coisas de aspecto: além do que nos diz o resultado estatístico (apenas 3 concordâncias em 17 pares), mesmo nos pares coincidentes divergem notavelmente as particularidades criminais. forçoso admitir, portanto, que o fator genético exerce pêso considerável nas impulsões para o crime.

2. A resultado análogo chegou um autor holandês, A. M. Legras, em 1932: os 4 pares de gêmeos idênticos, que estudou, apresentaram careiras criminais concordantes; os 5 pares de gêmeos fraternos tiveram carreiras discordantes. Menos expressiva, - embora depondo em análogo sentido, - é a estatística de STumpfl (Alemanha, 1936): em 18 pares de gêmeos idênticos, 11 concordâncias; em 19 pares de gêmeos fraternos, 7 concordâncias.

3. Heinrich Kranz (Alemanha, 1936), preocupado com o mesmo assunto, investiga a história de 74 pares de gêmeos, dos quais 31 idênticos e 43 fraternos: 20 concordâncias criminais para aqueles; 23 pşra êstes. $O$ autor não se contenta com os resultados estatísticos. Indagando pormenorizadamente, consegue verificar que "a concordância dos gêmeos idênticos se mostra muito mais acentuada que a dos gêmeos fraternos"; isto é, as carreiras criminais daqueles são quase idênticas; as dêstes geralmente diferem nas particularidades. "Devemos - assevera o autor — atribuir à hereditariedade um papel muito mais importante, na produção do crime, do que aquele que até aqui lhe temos reconhecido". Mas nem por isso se adotará a doutrina da 
predestinação: "a hereditariedade não pode ser responsabilizada, isoladamente, pelo destino". Os gêmeos idênticos discordantes estão a mostrá-lo claramente (10).

4. Em último lugar (pois que seu derradeiro trabalho veio a lume em 1941) está a investigação de Rosanoff e seus colaboradores, abrangendo 409 pares, com 137 de gêmeos idênticos e 272 de gêmeos fraternos: 119 concordâncias entre aqueles, 102 entre êstes. Mesmo nos casos dos três pares de gêmeos idênticos estudados no trabalho, em que os membros de cada par tiveram criação em meios distintos, "as manifestações anti-sociais foram, não só práticamente jguais em espécie e quantidade, mas também sincrônicas no ritmo de sua ocorrência" (11).

5. O quadro seguinte dá, em resumo, os resultados de tôdas as investigações sôbre gêmeos, em referência ao crime:

GEMEOS E CRIMINALIDADE

\begin{tabular}{|c|c|c|c|c|}
\hline \multirow{2}{*}{ Investigadores } & \multicolumn{2}{|c|}{ Gêmeos idênticos } & \multicolumn{2}{|c|}{ Gêmeos fraternos } \\
\hline & Concord. & Discord. & Concord. & Discord. \\
\hline $\begin{array}{l}\text { LANGE - Alem. } 1929 \\
\text { LEGrAS - Hol. } 1932 \\
\text { StUMPFL - Alem. } 1936 \\
\text { KraNZ - Alem. } 1936 \\
\text { RoSANOFF - E. U. } 1941\end{array}$ & $\begin{array}{r}10 \\
4 \\
11 \\
20 \\
119\end{array}$ & $\begin{array}{r}3 \\
0 \\
7 \\
11 \\
18\end{array}$ & $\begin{array}{r}3 \\
0 \\
7 \\
23 \\
102\end{array}$ & $\begin{array}{r}15 \\
5 \\
12 \\
20 \\
170\end{array}$ \\
\hline $\begin{array}{llll}\text { Total } & \ldots & \\
\text { Pocentagem } & & \end{array}$ & $\begin{array}{l}164 \\
86 \%\end{array}$ & $\begin{array}{l}39 \\
24 \%\end{array}$ & $\begin{array}{l}135 \\
40 \%\end{array}$ & $\begin{array}{l}222 \\
60 \%\end{array}$ \\
\hline
\end{tabular}

Tais resultados depõem pela influência da hereditariedade sôbre a conduta criminal: não fôra isso e não pre-

(10) Paul Popenoe - Twins and Criminals, Journal of Heredity, 27/380. O autor faz um resumo do livro de Kranz.

(11) V: em Journal of Heredity, 33/18, o resumo critico do trabalho de Rosanoff, Handy e Plesset. 
dominariam, invariavelmente, as coincidências entre os gêmeos portadores do mesmo equipamento genético. Mas afirmam também o influxo das fôrças ambientais, revelado através das discordâncias entre os gêmeos idênticos, assim como das concordâncias entre os outros.

6. De como é possível, por meio das fôrças ambientais, orientar o fator genético, a observação de um dos pares de LANGe nos dá conta. Ferdinando e Leopoldo, gêmeos idênticos, foram criados separadamente desde a idade de oito anos, sob condições ambientais bastante diversas. Leopoldo recebeu tratamento carinhoso, mas revelou-se displicente e ingrato para com os pais adotivos, para com os mestres e, mais tarde, para com a espôsa. Ferdinando, tratado com severidade, andou bem na escola; fugiu, depois, da casa adotiva para a de sua vó, onde o ambiente demasiado afetuoso que esta lhe proporcionou, fez dele, como do irmão, uma criatura imoral. Leopoldo, mais tarde, casou-se de novo; agora com uma mulher autoritária, de grande energia, que o forçou ao trabalho regular e o afastou das más companhias: tornou-se, então, afável, generoso, de convívioagradável; bom marido sentimental, "chegando a chorar na igreja" Sua mulher, entretanto, não confia muito nele e o mantém sob vigilância e disciplina. Não está aí, bastante clara, a possibilidade de se orientar o indivíduo pelo influxo. ambiental, a despeito da hereditariedade? A primeira espôsa de Leopoldo manteve-o na trilha do vício; a segunda: pô-lo na senda da virtude; aquela fez dele um ser anti-social; esta transformou-o em indivíduo produtivo. A conduta humana, em última análise, - quer a social, quer a anti-social, - é, como os demais caracteres, como o pêso corporal ou o grau de inteligência, o produto da hereditariedade e do ambiente. Melhore-se a hereditariedade; ou, se impossível, melhore-se o ambiente: ter-se-á, em ambos os. casos, caminhado no sentido do aperfeiçoamento do homem. 


\section{VI - Como atua a hereditariedade?}

1. A conduta do indivíduo em relação ao crime pode explicar-se pelo jôgo das fôrças "crímino-impelentes" e "crímino-repelentes", a que tantas vezes se referiu o prof. Di Tullio, nas memóraveis conferências que aqui pronunciou. Suponho que o "páleo-psiquismo" e o "neo-psiquismo", de que nos falou reiteradamente o mestre italiano, equivalem, aquele, ao "id", cego e instintivo; êste, ao "super-ego", civilizado e moral, da Psicanálise. Impulsos crímino-impelentes, todos nós os temos ao nascer, e nesse sentido todos nós somos criminosos-natos (12). Mas também recebemos capacidades latentes para organizar um sistema crímino-repelente, - um "super-ego" inspirado nos padrões morais da sociedade, - e cujos contra-impulsos dominam as inclinações delituosas (13).

A espécie "criminoso-nato" de Lombroso (depois de despojada de tôda a contribuição de epiléticos e de epileptóides com que foi originàriamenteé avolumada a respectiva estatística) reduz-se, hoje, à figura raríssima do chamado "Iouco moral", que se caracteriza pelo "deficit" mais ou me-. nos completo na capacidade de organizar um "super-ego" E êsse "deficit" tem base genética (14).

(12) Se as crianças pudessem agir de acôrdo com as suas fantasias, "o resultado seria uma criminalidade ativa de cem por cento" (Alexander e Staud - O Criminoso e seus Juizes, trad. de Ieonfbio Ribeiro, p. 54. "Todos nascemos criminosos-natos" (Flugel Man, Morals and Society, Londres, 1945, p. 190).

(13) O criminoso-nato, rarissimo (1 por 1.000, segundo MAYER) explicar-se-ia, para uns, como Dr Tullio, pelo excesso no vigor do id; para outros, como a maioria dos psicanalistas, pela deficiente for-mação de elementos básicos do super-ego; ou, ainda, pelo vigor da emotividade estênica (colérica, erótica).

(14) "Estas variações do equipamento instintivo são, sem dúvida, consideradas de natureza hereditária, - opinião que concorda com a de Freud e da maioria dos psicanalistas" (Flugel, op. cit.,. 
De muitas outras formas, entretanto, bem mais frequentes, pode influir a hereditariedade nas impulsões para o crime. O problema está por ora muito longe da solução integral; mas convém mencionar desde já algumas explicações, das quais deliberadamente excluimos os mecanismos mentais.

2. Certas anomalias corporais hereditárias (assim como as adquiridas), gerando no indivíduo um complexo de inferioridade, podem arrastá-lo ao crime. Os homens disformes, os de "má catadura" (15) encontram, para ambientar-se na vida amorosa ou social, maior dificuldade que os outros; são, mais frequentemente que os outros, of endidos pela zombaria e pelo desprêso, a cujos estímulos, aliás, se mostram muito sensíveis. David Abrahamsen cita casos de indivíduos que, por terem um pé torto ou por serem demasiado altos, se fizeram criminosos.

3. A hereditariedade pode conduzir ao crime também pelo "deficit" de inteligência. Aschaffenburg, Goring e GodDARD afirmavam mesmo que o tipo criminal se caracterizaria pela insuficiência intelectual. Não há dúvida que é essa, de fato, uma das veredas da hereditariedade para a delinquência. Mas as pesquizas recentes sôbre o assunto (Murachison, Sutherland, Zeleny, nos Estados Unidos; Cyril Burt, na Inglaterra) mostram que não é o único caminho, nem o mais frequente. $\mathrm{O}$ grau de inteligência concorre, menos para levar ao crime, do que para a escolha do tipo de delinquência.

4. Muito maior importância têm, no caso, os desequilíbrios afetivos - instabilidade emocional, maior reatividade aos traumas psíquicos da infância - tudo condicionado por

pág. 192). "Sabemos pouco a seu respeito, mas devemos reconhecer sua existência, com fundamento nas observações empiricas que repelem a afirmação de que todos os seres humanos nascem iguais" (Healy e Alexander - Roots of Crime, New York, 1935, pág. 2811).

(15) Para alguns antigos praxistas, a "má catadura" equivalia a uma leve presunção de criminalidade. 
fatores heredítários. Ocupou-se do assunto principalmente William Healy (Estados Unidos) (16).

5. Norwood EAST (Inglaterra) teme as desarmonias psíquicas, por heranças desproporcionadas vindas de um e de outro genitor (17).

E o mesmo temor de Davenport em relação às desarmonias somáticas. Viu êste último autor, na Jamáica, filhos que herdaram as pernas compridas do genitor preto e os braços curtos do genitor branco: ficaram desproporcionados e "com dificuldades para erguer as coisas que cáem no chão.." De maneira análoga, o filho poderia herdar as grandes ambições de um dos genitores e, concomitantemente, do outro genitor, os fracos meios para satisfazê-las. Receio que faltem, por enquanto, provas que fortaleçam a tese defendida por East.

Em resumo, muitos caminhos podem ser utilizados pela hereditariedade para levar ao crime: cada caso terá o seu. Muitos, salvo um, - o da herança direta de tendências especificamente criminais.

\section{:VII - Os meios profiláticos}

1. Com ou sem propósitos profiláticos, acreditando ou nẫo na influência genética sôbre a criminalidade, os antigos eram radicais: aplicavam a pena de morte aus reus dos delitos mais graves. Análogo resultado obtêm os códigos modernos que sujeitam êsses mesmos reus a longos prazos de reclusão.

Pelo advento da Genética, a profilaxia orientou-se para medidas de caráter mais científico, e, pode-se também dizer, cada vez menos violentas. Com efeito, a atitude dos

(16) William Healy e A. F. Bronner - New Lights on Delinquency and Its Treatment, New Haven, 1936. V. também HeARLy e Alexander - Roots of Crime, New York, 1935.

(17) Norwood EAST - Medical Aspects of Crime, Londres, 1936. 
que, inspirados na ciência de Mendel, têm procurado. de 1900 para cá, influir sôbre o aperfeiçoamento da espécie humana, passou sucessivamente por três fases.

2. A primeira foi a da Eugenia "negativa", cujo propósito essencial consistia em impedir a propagação do mau plasma germinativo. Daí o preconício da segregação, das restrições legais ao casamento, da esterilização. Esta última parecia mesmo ser a chave ideal da fecilidade humana. Mas a crítica fez arrefecer o entusiasmo pelos métodos negativos em geral; a pouca eficácia estatística pôs a esteriiização de quarentena. No que diz respeito aos criminosos, teve esta a repulsa mais formal, dada a obscuridade que ainda reina em tôrno dos mecanismos de transmissão genética das impulsões para o crime (18).

3. A segunda fase foi a da Eugenia "positiva", que visa sobretudo facilitar a propagação do bom plasma germinativo. Derivam dela os programas de estímulo ao casamento precoce dos "bem dotados" e de prêmio aos "bem dotados" prolíficos. Na onda cada vez mais volumosa de produtos. superiores, diluir-se-iam e tornar-se-iam práticamente inócuos os produtos inferiores.

4. Antes, porém, que a Eugenia positiva começasse sequer a ser posta em execução, sobreveio a terceira fase. Adiam-se por ora os métodos eugênicos; apela-se preliminarmente para a Eutenia; isto é, para a Higiene e a Educação. Não porque se espere que a Eutenia, aplicada a uma geração, melhore, segundo o lamarquiismo, os produtos da geração seguinte. Não: os benefícios colhidos pelo indivíduo sob o influxo da Higiene e da Educação, biológicamente só a ele beneficiam, não se transmitem à sua descendência.

o grande benefício das medidas eutênicas está em que elas ensejam o pleno desenvolvimento das fôrças genéticas: vantajosas, em lugar de inibí-las. Neste sentido, - e para: concluir esta já longa dissertação - quero reproduzir as:

(18) Vide Eugenical Sterilization - Committee of the American Neurological Association, N. York, 1936. 
significativas afirmações dos maiores geneticistas contemporâneos, feitas no "Manifesto" que publicaram por ocasião do Sétimo Congresso Internacional de Genética, reunido em Edinburgo em agosto de 1939, justamente nos dias que precederam à última guerra.

"O aperfeiçoamento genético da humanidade (declararam eles) depende de consideráveis alterações nas condições sociais, de correlativas mudanças nas atitudes humanas.

"Em primeiro lugar, não pode haver bases válidas para calcular e comparar o valor intrínseco dos diferentes indivíduos, sem condições econômicas e sociais que ensejern oportunidads aproximadamente iguais a todos os membros da sociedade, em lugar de estratificá-los desde o berço em classes com graus tão diversos de privilégios.

"O segundo grande obstáculo ao aperfeiçoamento genético, está nas condições econômicas e políticas que alimentam o antagonismo entre os povos, as nações e as "raças". A supressão dos preconceitos de raça e da anti-científica doutrina de que os bons ou maus "gens" são o monopólio de certos povos ou das pessoas com certa aparência fisionômica, não será possível, contudo, antes que as condições que permitem a guerra e a exploração econômica tenham sido eliminadas. Isto requer uma espécie de federação mundial, baseada no interêsse comum de todos os povos."

O "Manifesto" continua, logo abaixo: "Uma compreensão mais larga dos princípios biológicos trará a conviç̧ão. de que devemos ambicionar muito mais do que prevenir a deterioração genética; e também de que a elevação da população, em geral, até ao alto nível presentemente só alcançado por indivíduos isolados, em relação ao bem estar físico, à inteligência e às qualidades temperamentais, é realização que poderá - ao menos do ponto de vista genético. - ser materialmente obtida dentro de número relativamente pequeno de gerações." 
E assim concluem os geneticistas de Edinburgo: "Isto só se atingirá quando o espírito humano se libertar da preocupação da guerra, do ódio, e bem assim da luta pelos meios elementares de subsistência, orientando-se então em busca de objetivos mais altos, num esfôrço comum. O dia para que a reconstrução econômica possa ensejar essa libertação das fôrças humanas, ainda não chegou; mas cabe a esta geração o dever de prepará-lo" (19).

(19) Journal of Heredity, 30/371. 